\title{
Evaluating the feasibility and acceptability of the Healthy Together program for immigrant and refugee families in Canada
}

\author{
Anne Huisken, Joan L. Bottorff and Catherine Nesmith
}

\begin{abstract}
Purpose - Healthy Together (HT) is an innovative family education program focused on bringing families together to promote physical activity and healthy eating. The HT program was implemented in 10 community-based organizations across Canada offering services to immigrant and refugee families. The purpose of this study was to explore the feasibility and acceptability of HT when offered to these families.

Design/methodology/approach - A cross-sectional, non-comparative design was used. Caregiver participants were invited to complete a survey at the end of 15, 30 or 24 HT sessions. Trained program facilitators and directors of community-based organizations also provided feedback on the program.

Findings - Among the 203 caregiver participants, 135 (64\%) were born outside of Canada. These caregivers were more likely to attend $50 \%$ or more of the HT sessions than Canadian-born caregivers. Survey responses show that the HT program was acceptable to immigrant and refugee caregivers and held important benefits for families including positive changes in healthy eating and physical activity, strengthening social connections and learning about community services and resources. Areas for enhancing the HT program for immigrant and refugee families were identified by participant caregivers and community organizations delivering the program.

Practical implications - The HT program demonstrates the value of family-centered program models in supporting immigrant and refugee families in establishing healthy lifestyles and building social connections in ways that hold promise for long-term impact.

Originality/value - The HT program model demonstrates strong potential to fill gaps in community programming for immigrant and refugee families. Although focused on promoting healthy lifestyles, the program extends additional benefits that can positively influence resettlement trajectories. The findings contribute to the growing field of implementation studies that are focused on expanding the reach and impact of community health interventions in a real-world setting while reaching multiple target populations.
\end{abstract}

Keywords Resettlement, Program evaluation, Newcomers, Family health, Healthy lifestyles, Obesity prevention

Paper type Research paper

\section{Introduction}

Globally, the rising rates of childhood overweight and obesity are a serious public health concern. Early intervention is paramount because childhood obesity can lead to comorbidities such as metabolic syndrome, cardiovascular disease, Type 2 diabetes, poor emotional and social health and obesity and overweight in adulthood (Sahoo et al., 2015; Reilly and Kelly, 2011; Weiss et al., 2004).

Immigrant children represent a substantial and growing portion of the Canadian population. Results from the 2016 Canadian Census estimated that 2.2 million children under the age of 15 were foreign-born and represented $37.5 \%$ of all Canadian children. Projections indicate that by 2036 immigrant children will represent $49 \%$ of the population under 15 years of age
Anne Huisken and

Joan L. Bottorff are both based at the Institute for Healthy Living and Chronic Disease Prevention, The University of British Columbia, Kelowna, Canada. Catherine Nesmith was based at The Bridge Youth and Family Services, Kelowna, Canada.

Received 20 December 2019 Revised 10 July 2021 10 August 2021 Accepted 7 September 2021

(C) Anne Huisken, Joan L. Bottorff and Catherine Nesmith. Published by Emerald Publishing Limited. This article is published under the Creative Commons Attribution (CC BY 4.0) licence. Anyone may reproduce, distribute, translate and create derivative works of this article (for both commercial and non-commercial purposes), subject to full attribution to the original publication and authors. The full terms of this licence may be seen at http://creativecommons.org/licences/by/4.0/ legalcode

The work is supported by the Public Health Agency of Canada (Grant \#1415-HQ000818) to The Bridge Youth and Family Services, Kelowna, BC, Canada.

We thank the community organizations for taking time to help us evaluate Healthy Together, and the families for their thoughtful comments and suggestions to help us improve the program. 
(Statistics Canada, 2017). Although little published literature exists on the relationship between childhood obesity and immigration (Sanou et al., 2014), an increased risk of overweight and obesity among some groups of immigrant children has been demonstrated, as well as evidence that this excess risk increases as children grow older (Zhang et al., 2019; Zulfiqar et al., 2018). Related to this is evidence that immigrant children experience a steady decline in their cardiovascular profiles after arriving in their new countries (Lane et al., 2018).

Variations in overweight/obesity among diverse immigrant groups indicate that the underlying factors are complex and extend beyond socio-economic factors to include factors such as cultural or ethnic backgrounds, time since immigration and influences within the host environment. Differences in the prevalence of overweight and obesity among immigrant adults within and between ethnic groups in Canada have been observed and related to a number of factors including cultural norms related to nutrition (e.g. dietary customs and acceptable foods), physical activity (e.g. sex and age-specific activities) and time since immigration (Tremblay et al., 2005; Tremblay et al., 2006). Perceptions related to acceptable weight ranges and what a healthy weight is for children can also be influenced by cultural norms, as well as pre-immigration experiences (e.g. related to malnutrition and food scarcity) (Dawson-Hahn et al., 2020).

Most immigrant families undergo a lifestyle transition as part of their resettlement experience. This transition can involve dietary shifts contributing to increased intake of fat, sodium and sugary drinks (Lane et al., 2018; Sanou et al., 2014) and a shift to more sedentary lifestyles, both contributing over time to an increased risk of overweight among some immigrant groups (Tremblay et al., 2005). Diet and physical activity remain important modifiable risk factors in preventing obesity-related chronic diseases in children (Kipping et al., 2008). Therefore, immigrant caregivers and children may benefit from programs and services that promote healthy lifestyles. Nevertheless, approaches are likely to be more successful if they account for factors such as cultural beliefs/practices and the diversity of experiences among immigrant families.

To identify knowledge gaps and research priorities related to nutritional health among immigrants to Canada, Sanou et al. (2014) conducted a scoping review. Among the research priorities identified were improved access and outreach to immigrant groups and finding effective health promotion strategies for immigrants, which, in addition to nutrition education, address social determinants of health. Community-based interventions are proposed as a feasible strategy to reach marginalized communities including immigrant families (Candib, 2007).

In obesity prevention research, family-based approaches are increasingly recognized as a promising way to promote health behaviors (Lindsay et al., 2006). Parents and caregivers can reinforce eating and physical activity, influence the availability of healthy food and establish family routines to support the development and sustainability of new healthy habits. The involvement of parents/caregivers has also has been shown to improve family relationships (Van Ryzin and Nowicka, 2013) and decrease the number of meals eaten outside of the home (Robson et al., 2016).

Healthy Together $(\mathrm{HT})$ is an innovative family education program focused on bringing families together to promote physical activity and healthy eating (Bottorff et al., 2021). The HT program is modeled on three integrated components, namely, a learning activity promoting healthy weights, cooking and eating together and physical activity. Each of the group-based interactive sessions provides families with tools and resources to improve their knowledge and confidence in areas of healthy eating and physical activity and bring families together in an interactive setting to learn about healthy lifestyles. Trained facilitators are provided with an HT toolkit and supporting resources for the HT sessions. At the organization level, facilitators delivere the program supported by program assistants and 
directors oversee the implementation of the program at their organization. For more information see http://healthy-together.ca/.

Although $\mathrm{HT}$ is not specifically tailored to immigrant populations, the program was designed to be adaptable to meet the needs of diverse families. Between 2017 and 2019, the program was offered in 10 community-based organizations serving immigrant and refugee families. Facilitators were encouraged to adapt HT for integration into core service programs and to meet the needs of families and support their transitions into life in Canada. This study was conducted to examine the acceptability and feasibility of the HT program from the perspective of immigrant and refugee caregiver participants attending the program with their children, facilitators and directors of participating organizations and to provide direction for future refinements to the HT program for delivery with immigrant and refugee families to support lifestyle transitions in a new country.

\section{Methods}

Using a cross-sectional, non-comparative design, a community-based program evaluation was conducted. The study received ethical approval from the Behavioral Research Ethics Board at the University of British Columbia (H17-01200).

\section{Participating community organizations}

In Canada, community-based organizations play an important role in providing familycentered services and programs. Based on the capacity to integrate HT into existing core service programs, 10 community-based organizations providing services to immigrant families were offered the opportunity to implement HT. Participating organizations were required to sign a contract agreeing to terms of service for program delivery and were provided $\$ 7,000$ Canadian to support program delivery. Organizations were also offered the opportunity to apply for additional funding to support language translation services. Only one organization applied and received this funding. The majority of community organizations $(n=9 / 10)$ were contracted to deliver $30 \mathrm{HT}$ sessions and one site was contracted to deliver 24 sessions in 2 different communities. One staff member from each organization attended the HT facilitator training program. Implementation took place between May 2017 and January 2019.

\section{Participants}

Parents, other caregivers and children (0-12years) were recruited to participate in HT through the regular programing provided by participating organizations. In some organizations, registration for HT was required, while others offered HT as a drop-in program. Program participants attending HT on the 15th, 30th or 24th session were invited to participate in the evaluation of HT. Facilitators and directors at participating organizations were also included in the program evaluation.

\section{Data collection}

Self-report data collection tools were used to measure outcomes among HT caregiver participants. Staff at participating organizations invited caregivers to complete feedback forms as a closing activity during the delivery of the first and second set of 15 sessions or the 24th session. When necessary, caregiver participation in the evaluation was supported by providing access to in-house language translation services. Information about the study was provided in a cover page to the survey; completion and return of the surveys by caregivers implied consent. The caregiver feedback form included questions to collect data related to child(ren) outcomes. Although brief, age-appropriate evaluation forms were available for children six years and older, facilitators did not ask immigrant and refugee 
children with limited English proficiency to complete the feedback forms. As the majority of children participating in these HT programs were under the age of six years and very few feedback forms were completed by older children, their feedback forms were not included in this analysis.

HT facilitators completed evaluation forms following delivery of 15 and $30 \mathrm{HT}$ sessions or at the end of the program when 24 sessions were offered. Directors participated in two short telephone interviews after their organization had implemented the first set of $15 \mathrm{HT}$ sessions and six months after delivering the second set of $15 \mathrm{HT}$ sessions. For organizations implementing 24 sessions, directors were invited to participate in an interview after all 24 sessions were delivered and at a six-month follow-up. Both interviews included open-ended questions that asked about the organization's experience in offering HT, how well the HT program supported organizational efforts to meet the needs of families, and additional resources and support required to deliver $\mathrm{HT}$ and program adaptations. Following informed consent, semi-structured telephone interviews were conducted, recorded and transcribed verbatim.

\section{Participant measures}

Caregiver characteristics. Caregivers reported on their age, sex, if they were born in Canada (yes or no) and their country of birth. Respondents with missing data on their country of birth were excluded from the analysis $(n=8)$. Engagement in regular physical activity was measured using the Godin Physical Activity Leisure time questionnaire (Godin and Shephard, 1985) to assess if respondents were meeting the recommended physical activity requirements of $150 \mathrm{~min}$ of moderate to vigorous physical activity (MVPA) per week. Data were used to categorize participants as either meeting the MVPA requirement ( $>150$ min per week) or not meeting this requirement (Amireault and Godin, 2015). To assess patterns of healthy eating, caregivers reported how often their family consumed sugary drinks and ate foods high in sodium, whole grains and fruits/vegetables. Response options were, namely, everyday, a few times a week, a few times a month and not at all.

Attendance. Caregivers reported on the number of sessions of HT they attended. To compare participant outcomes based on attendance, participants were dichotomized into those who had attended $<50 \%$ of HT sessions offered within each organization and those who attended $\geq 50 \%$ of the sessions offered.

Healthy Together program outcomes. Using the stem "as a result of coming to Healthy Together," caregivers reported if they had: a) learned about healthy food for their family, b) planned to make healthy, c) low cost meals for their family more often and d) if they knew where to buy healthy, low-cost foods. Response options for all four questions were, namely, yes, no or not sure. If yes was selected for question a or c, caregivers were asked to provide examples. They were also asked about family sugary drink consumption and eating fruits and vegetables as a result of the HT program using a five-point Likert scale ( $1=$ much less often to $5=$ much more often).

Caregivers rated how helpful the HT program was in teaching them about physical activity for their family using the following response options: very helpful, somewhat helpful and not very helpful. To assess change in physical activity behaviors, participants responded to two questions, namely, as a result of the Healthy Together program... how physically active are you now than before the program? How active is your child (or your children) than before the Healthy Together program? A five-point Likert scale was used ( $1=$ much less active to $5=$ much more active).

Caregivers reported on HT's effectiveness in improving relationships with their family, helping them make friends with other participants, learning about community resources and 
feeling connected to their community. Ratings of effectiveness were reported using a fivepoint Likert scale $(1=$ not effective to $5=$ very effective).

Healthy Together program acceptability. Caregivers were asked how easy it was to fit the information from HT into their cultural practices using response options, namely, very easy, easy, somewhat difficult, very difficult and does not apply. They also reported on how respectful HT sessions were of their culture. Response options included: not very respectful, a little respectful, somewhat respectful and very respectful. Perceived usefulness of the HT program was assessed using the following response options, namely, not very useful, a little useful, somewhat useful and very useful. Participants were also asked if they would refer others/their friends to the HT program (yes/no).

Impacts on personal well-being. In a multiple response question, caregivers were asked if they noticed any changes in their personal lives because of the HT program. Response options included: I feel healthier, I feel happier, I am less stressed, I saved money on groceries, I am having more fun with my family, I feel more comfortable meeting and talking to new people, my English has improved, I lost weight, no change and other (specify).

\section{Organizational data collection}

Facilitators completed a program implementation summary and a questionnaire that included questions about their observations of the effectiveness and usefulness of the program. Using open-ended questions, facilitators were asked to describe any adaptations or changes they made to the program for immigrant/refugee families and to describe the benefits of these adaptations.

Directors were also interviewed and asked to comment on how well the HT program meet the needs of the families they served. Directors were asked to identify additional resources they supplied to offer the HT program (e.g. extra staff, food, equipment, space, etc.) and challenges experienced in offering the program to immigrant/refugee families.

\section{Data analysis}

All data were identified using coded numbers. Survey data were entered into SPSS (v.25) and analyzed using descriptive statistics such as frequencies, means and standard deviations. Differences between immigrant and refugee caregivers and Canadian-born caregivers were assessed using Person's Chi-square tests for categorical variables and independent sample $t$-tests for continuous variables. Significance levels were set to $P \leq$ 0.05 . To explore differences among ethnic/cultural groups, we categorized immigrant and refugee caregivers by country of origin: Asian $(n=50)$, Latin American/Caribbean $(n=16)$ and African and Middle Eastern $(n=40)$. Interview data were transcribed verbatim by a trained research assistant. Qualitative data were content analyzed using NVivo (v. 12).

\section{Results}

In total, 203 caregivers participated in the HT evaluation. Of the 358 caregivers attending $\mathrm{HT}$ at the time of data collection at participating sites, 144 caregivers completed the survey (response rate $=40.2 \%$ ). At one site, eight newly arrived refugee caregivers residing in a welcome center completed the survey as they left the HT program to move to their new communities. At three sites, staff administered the survey over a number of days to accommodate language and literacy levels. These surveys $(n=51)$ were either completed as one-on-one interviews or in small groups with translators.

At three sites, the HT program was only offered to immigrant and refugee families (e.g. an immigrant welcome center and an immigrant service center). At all other sites, both immigrant/refugee families and Canadian-born families attended HT. Among the 203 caregivers in the respondent sample the majority were female $(n=194,91.9 \%), 135$ 
caregivers (64\%) were born outside of Canada and 68 caregivers (36\%) were born in Canada. The sample included families from: Asia (12), South Asia (28), Southeast Asia (13), Africa (15), Europe (7), the Middle East (25), the UK (5) and the Americas/Caribbean (16). Some participants $(n=14)$ who indicated they were born outside of Canada did not list their country of birth.

There were no significant differences between caregivers born outside of Canada and Canadian-born caregivers with respect to age and health behaviors related to physical activity and dietary behaviors (Table 1). Immigrant and refugee participants were more likely to attend $50 \%$ or more of HT sessions offered at community organizations than Canadian-born caregivers $\left(X^{2}=13.09, P<0.001\right)$.

\section{Healthy Together program outcomes for immigrant and refugee caregivers}

Physical activity. Immigrant and refugee caregivers were significantly more likely than Canadian-born caregivers to report that HT was helpful in teaching them about physical

Table 1 Characteristics of healthy together participant caregivers $(n=203)$

\begin{tabular}{|c|c|c|c|}
\hline Measure & $\begin{array}{l}\text { Immigrant and refugee caregivers } \\
\qquad(\mathrm{n}=135)\end{array}$ & $\begin{array}{l}\text { Canadian-born caregivers } \\
\qquad(\mathrm{n}=68)\end{array}$ & Significance \\
\hline $\begin{array}{l}\text { Ageł } \\
\text { Sex (women) }\end{array}$ & $\begin{array}{r}35.52( \pm 8.28) \\
128(94.6 \%)\end{array}$ & $\begin{array}{l}36.96( \pm 9.4) \\
66(97.1 \%)\end{array}$ & $\begin{array}{l}t=-1.10(\mathrm{df} 194)(P=0.274) \\
\text { Fishers exact }(P=0.72)\end{array}$ \\
\hline $\begin{array}{l}\text { Attendance patterns } \\
\text { Attended } \leq 50 \% \text { of HT sessions } \\
\text { Attended }>50 \% \text { of HT sessions } \\
\text { Missing }\end{array}$ & $\begin{array}{l}53(39.3 \%) \\
65(48.1 \%) \\
17(12.6 \%)\end{array}$ & $\begin{array}{l}46(67.6 \%) \\
17(25 \%) \\
5(7.4 \%)\end{array}$ & $X^{2}=13.09(P<0.001)$ \\
\hline $\begin{array}{l}\text { Physical activity guidelines } \\
\text { Meet MVPA guidelines } \\
\text { Does not meet guidelines } \\
\text { Missing }\end{array}$ & $\begin{array}{l}65(48.1 \%) \\
52(38.6 \%) \\
18(13.3 \%)\end{array}$ & $\begin{array}{r}19(27.9 \%) \\
42(61.8 \%) \\
7(10.3 \%)\end{array}$ & $X^{2}=2.96(P=0.09)$ \\
\hline $\begin{array}{l}\text { Dietary patterns } \\
\text { Drink sugary drinks \% } \\
\text { Everyday } \\
\text { A few times a week } \\
\text { A few time a month } \\
\text { Not at all } \\
\text { Missing }\end{array}$ & $\begin{array}{l}17(12.6 \%) \\
25(18.5 \%) \\
54(40 \%) \\
37(27.4 \%) \\
2(1.5 \%)\end{array}$ & $\begin{array}{c}4(5.9 \%) \\
18(26.5 \%) \\
26(38.2 \%) \\
19(27.9 \%) \\
1(1.5 \%)\end{array}$ & $X^{2}=3.34(P=0.34)$ \\
\hline $\begin{array}{l}\text { Foods high in sodium } \\
\text { Everyday } \\
\text { A few times a week } \\
\text { A few time a month } \\
\text { Not at all } \\
\text { Missing }\end{array}$ & $\begin{array}{l}19(14.1 \%) \\
41(30.4 \%) \\
42(31 \%) \\
29(21.5 \%) \\
4(3 \%)\end{array}$ & $\begin{array}{c}7(10.3 \%) \\
20(29.4 \%) \\
25(36.8 \%) \\
13(19.1 \%) \\
3(4.4 \%)\end{array}$ & $X^{2}=1.07(P=0.78)$ \\
\hline $\begin{array}{l}\text { Whole grains } \\
\text { Everyday } \\
\text { A few times a week } \\
\text { A few time a month } \\
\text { Not at all } \\
\text { Missing }\end{array}$ & $\begin{array}{c}80(59.3 \%) \\
42(31.1 \%) \\
6(4.4 \%) \\
- \\
7(5.2 \%)\end{array}$ & $\begin{array}{l}49(72.1 \%) \\
16(23.5 \%) \\
3(4.4 \%) \\
- \\
-\end{array}$ & $X^{2}=1.92(P=0.38)$ \\
\hline $\begin{array}{l}\text { Fruits and vegetables } \\
\text { Everyday } \\
\text { A few times a week } \\
\text { A few times a month } \\
\text { Not at all } \\
\text { Missing }\end{array}$ & $\begin{array}{c}113(83.7 \%) \\
17(12.6 \%) \\
- \\
- \\
5(3.7 \%)\end{array}$ & $\begin{array}{l}64(94.1 \%) \\
4(5.9 \%) \\
- \\
- \\
-\end{array}$ & $X^{2}=2.43(P=0.12)$ \\
\hline
\end{tabular}


activity for their family $\left(n=91,67.4 \% ; X^{2}=11.67, P=0.003\right)$ and were more likely to report increases in children's physical activity $\left(X^{2}=10.84, P=0.004\right)$ and their own $\left(X^{2}=12.6, P=\right.$ 0.002) as a result of HT. Immigrant and refugee caregivers from Asian ( $n=40 / 50,78.4 \%)$ and South American/Caribbean countries ( $n=12 / 16,75 \%)$ were more likely to report increases in their children's physical activity because of $\mathrm{HT}$, compared to those from African/Middle East countries ( $n=19 / 39,1$ missing answer, 48.7\%) $\left(X^{2}=9.36, P=0.009\right)$. However, no significant sub-group differences were observed with respect to reports of caregiver personal physical activity. All caregiver groups were similar in their reports of increased physical activity as a family as a result of HT. Notably, $65.9 \%(n=89)$ immigrant and refugee caregivers reported that because of $\mathrm{HT}$ that their families engaged in more physical activity together.

Healthy eating. Immigrant and refugee caregivers reported that as a result of HT they learned about healthy food for their families $(n=120,88.9 \%)$, how to make healthy meals and snacks for their family $(n=112,83 \%)$ and where to buy low cost food in their communities ( $n=88,65.2 \%)$. They also reported they could find low-cost foods at major chain grocery stores, ethnic grocery stores and farmer's markets, as well as how to save on their grocery bill by shopping with flyers/coupons and purchasing sale items.

Immigrant and refugee caregivers also reported that because of HT their family ate fruits and vegetables more often $(n=100,74.1 \%)$ and that their family consumed sugary drinks less often ( $n=84,62.2 \%)$. There were no significant differences among immigrant and refugee caregivers grouped by country of origin (Asian, South American/Caribbean and African/Middle Eastern) related to consumption of sugary drinks or eating fruits and vegetables. However, immigrant and refugee caregivers were significantly more likely to report that they ate fruits and vegetables more often because of coming to HT ( $X^{2}=7.14$, $P=0.03)$ than Canadian-born caregivers. In relation to other indicators of healthy eating, there were no significant differences between immigrant and Canadian-born caregiver groups.

Social connections and community resources. The majority of immigrant and refugee caregivers reported that $\mathrm{HT}$ was effective in improving relationships with their family $(n=96$, $71.1 \%)$, helping them make friends with other participants ( $n=109,80.7 \%$ ), enabling them to learn about community resources $(n=102,75.6 \%)$ and helping them feel connected to their community $(n=99,73.3 \%)$. Through participation in the HT program, they also reported accessing other services or programs at local community centers including community kitchens, women's resource centers, local preschool programs, recreation centers and parks. In relation to social connections and community services, immigrant and refugee caregivers were significantly more likely to report that $\mathrm{HT}$ helped them learn about community resources $\left(X^{2}=6.72, P=0.04\right)$ and feel connected to their community $\left(X^{2}=\right.$ $7.49, P=0.02)$ compared to Canadian-born caregivers. For other indicators, there were no significant differences between these caregiver groups.

Program acceptability. Although most immigrant and refugee caregivers perceived that it was easy to fit information from HT into their cultural practices $(n=113,83.7 \%)$, a few reported that this was difficult $(n=12,8.8 \%)$. The majority reported that the HT program was respectful of their culture $(n=123,91.1 \%)$ and that the HT sessions were useful to them $(n=120,88.9 \%)$. Specifically, participants enjoyed sharing and preparing food with their children and other caregivers, meeting new people in their communities and learning about new cultures. Most reported that they would definitely refer others to the program ( $n=$ $114,84.4 \%)$.

Immigrant and refugee caregivers suggested that HT could be improved by involving families in choosing meals and snacks, including more cultural diversity in the programming, increasing the length of the program sessions and offering more sessions. Others requested more time for physical activity, spending more time outdoors (e.g. field trips), involving children in more cooking activities, offering the program in other languages 
and providing access to the online $\mathrm{HT}$ resources. Some immigrant and refugee caregivers also suggested that their family required financial support to participate in the program such as bus tickets or transportation to attend HT and improved access to affordable healthy foods.

Impacts on personal well-being. Immigrant and refugee caregiver reports of improvement in their personal well-being attributed to HT are shown in Table 2. Multiple answers were encouraged.

\section{Experiences in delivering Healthy Together}

Data related to experiences in program delivery were provided by 40 facilitators and 8 directors from the 10 participating sites. All facilitators and directors reported adapting HT activities to meet the needs of program participants and foster program engagement. Common adaptations to cooking activities included sourcing more culturally diverse recipes and accommodating religious and cultural dietary restrictions. HT activities were also adapted to celebrate cultural holidays (e.g. Chinese New Year) and celebrate international events (e.g. Winter Olympics).

Some organizations invited participants to lead HT activities and share cultural practices with the group. For example, one facilitator shared an experience to illustrate the unique learning experience this provided for all participants while supporting HT program messages:

We made homemade... whole wheat pitas ... to go along with the hummus recipe from the [HT] binder. Our [cooking] lead... was a Kurdish participant from northern Iraq. Her 4-year old daughter gave the adult participants a run for their money in pita making. They were great role models to show parents how much fun it is to cook with kids. (Facilitator, Community organization, serving primarily new immigrant families)

About half of the facilitators ( $n=19,47.5 \%$ ) reported making new connections to services and professionals in their community because of offering HT. Connections with professionals included public health nurses, dietitians, social workers and dental hygienists. Services included local food assistance programs and employment programs. Some organizations also offered field trips to local recreation centers, libraries, community parks, farms and gardens to introduce families to free family-friendly events in the community. Over the course of $\mathrm{HT}$, families benefited from invited guest speakers, increased access to primary health care and services and social outings.

Directors described HT as providing a safe and inclusive environment that enabled families a way to explore healthy eating and physical activity from a Canadian perspective. When commenting on the effectiveness of HT in meeting the needs of participants, directors often

Table 2 Reports of the impact of Healthy Together on personal well-being among immigrant and refugee caregivers $(n=135)$

I am more comfortable meeting new people

I am having more fun with my family 
described the daunting process that immigrant and refugee families faced when settling into their new communities. In addition to a myriad of upstream factors such as securing employment, housing and adequate financial resources, families also faced culture shock and language barriers, as well as stress and trauma. Although most directors thought that HT met the needs of immigrant and refugee families, others thought that for families dealing with many issues HT did not help them to directly address these needs. However, all directors believed that HT was "a really positive experience" for families and provided an important opportunity to connect with other families in their new communities:

It's a really stressful time for families, so it is nice to offer them a short break. When you have food, it always brings people together... The parents are really eager to participate and bring new ideas... It's so nice to see that... when you work with refugee families, you never know, people seem stressed and traumatized." (Director, Immigrant Settlement Center)

Most organizations also provided language translation and support services to families attending HT. Directors reported that program preparation could be time consuming for their staff, particularly at organizations where program materials and resources needed to be translated. When HT was offered as a drop-in program, estimating resources (e.g. food for the cooking component) for HT sessions was often a challenge because families varied in size.

\section{Discussion}

This study explored the feasibility and acceptability of offering a family health promotion program to immigrant and refugee families in Canada. Overall, the acceptability of the HT program was indicated by the robust attendance rates by immigrant and refugee families and general agreement among facilitators and directors about the value of the program for families. The impact of the program indicated improvements in healthy eating and physical activity among immigrant and refugee families. In addition, evidence of enhanced social connections, increased knowledge of community resources and services and, in some cases, improved English literacy as a result of HT were also important outcomes. Given these results, the HT program demonstrates the potential for long-term benefits for immigrant and refugee caregivers and their children.

Unlike our experiences with HT, some communities have reported challenges in recruiting immigrant families to existing health promotion programs. Reasons suggested for this include a lack of tailored programs for immigrant groups and the expectation that everyone will participate in mainstream programs offered in the community (Khan and Kobayashi, 2017; Renzaho et al., 2018). Based on a case study of a sport and recreational organization's newcomer inclusion program, Forde et al. (2015) recognized the challenges of promoting social inclusion and concluded that efforts to engage newcomers fail when organizational practices are aimed at assimilation by focusing on reducing barriers, minimizing differences and expecting everyone to fit in. Further, they suggest that both tailored and mainstream approaches fall short of providing families with opportunities for intermingling and mutual learning, where differences can be embraced. In our study, recruitment into the HT program was facilitated by partnering with local community-based organizations offering services to immigrant and refugee families and integrating $\mathrm{HT}$ into existing services. Both strategies helped to address barriers to participation. In addition, built-in flexibility in the HT program enabled facilitators to adapt program materials and activities in ways that accounted for diverse cultural/ethnic practices and family needs. Despite the challenges that this posed for facilitators in community organizations that served Canadian-born caregivers and children, as well as diverse immigrant families, the HT program provided an important opportunity for two-way learning and intra-cultural understanding. 
Although HT has was not specifically designed for immigrant and refugee families, the findings indicate that $\mathrm{HT}$ has strong potential to fill gaps in current community programming targeting immigrant and refugee families. Among all caregiver groups, few met physical activity requirements. Nevertheless, immigrant and refugee caregivers were more likely to report improvements in their children's and their own physical activity as a result of the HT program than Canadian-born caregivers. Immigrant and refugee caregivers were also more likely to report their family ate more fruits and vegetables as a result of the HT program than Canadian-born caregivers. These findings support the value of community-based interventions with an integrated family-focused learning approach to improve diet and physical activity behaviors (Thompson et al., 2003).

Important areas of focus to support improved health behaviors among refugee caregivers with young children have been suggested by Dawson-Hahn et al. (2020). These include providing a safe place for families to engage in physical activity, access to fresh foods and information about healthy diets, the latter being particularly important for families who have experienced food scarcity. These foci are all central components of the HT program. However, while the HT program enabled immigrant and refugee caregivers to find low-cost foods in their community, some caregivers expressed the needs for financial support and improved access to affordable healthy foods. Community-based organizations offering services to immigrant and refugee families are ideally positioned to address these needs. Further, HT provides a platform that has the potential to be leveraged to support policy or system level changes at the organization and community level to improve access to affordable foods. Similarly, the HT program enabled immigrant families to engage in physical activity in a safe and welcoming environment. Improvements in physical activity are more likely to be sustained when families have access to supportive environments within organizations and communities (Wieland et al., 2015). Our findings also indicate that additional efforts may be needed to support physical activity particularly among some ethnic/cultural groups such as families from African and Middle Eastern countries.

For immigrant and refugee families, the HT program provided a particularly important avenue for the development of social connections, increased knowledge of community resources and services and, in some cases, improved English literacy - all factors that influence resettlement trajectories. Immigrant and refugee caregivers also reported improved personal well-being because of the HT program. These HT program benefits are supported by an independent social return on investment analysis of the HT program. Specifically, for immigrant and refugee families the results of this analysis indicated that the improved social connections, language skills and ability to adapt to Canadian living attributed to participation in HT resulted in the estimated value of $\$ 415$ per family (SiMPACT, 2019). Together these findings demonstrate that HT positions immigrant and refugee caregivers to support their family's lifestyle transitions and resettlement experiences with promise for long-term impact.

The HT program outcomes are importantly a reflection of the skill set of the facilitators in adapting HT to meet the needs of immigrant caregivers and children. These adaptations demonstrated facilitators' sensitivity to the challenges experienced by families, as well as the way they valued diversity and promoted social inclusion. Access to family health promotion programs such as HT may be best supported by integrating these programs into community organizations where there is expertise in offering services to meet the needs of diverse immigrant and refugee families. Furthermore, by integrating family health promotion programs such as HT into community organizations offering services to immigrant and refugee families, those affected by conflict and violence in their home countries, stigma or language barriers can be supported to access needed programs and services to promote their well-being and adaptation.

Although community organizations found the HT program resources useful, they reported that translating key resources was costly and time consuming. Providing translations of key 
HT program resources and take-home materials in the HT toolkit will facilitate future program delivery and, importantly, help to mitigate language barriers and increase learning for those with lower English or French proficiency. Moreover, future program materials and images should also aim to represent the diversity of immigrant families. Future enhancements to the HT program could also be guided by consultations with key stakeholders and diverse groups representing immigrant and refugee families to enable the development of program resources directly informed by their needs and lived experiences.

HT's flexible and adaptable program model enabled implementation in diverse organizations and communities thereby offering a promising scalable model for extending the reach of family-focused health promotion programming. This type of model is particularly important for addressing the range of social, economic, cultural and historic factors that influence immigrant families and their ability to engage effectively in health promotion programs.

Despite the success of the HT program, the program primarily engaged female immigrant caregivers and their children. In light of growing interest to recognize men's involvement in child health and well-being, as well as the need to ensure gender equity in program design and delivery (Oliffe et al., 2020; Morgan and Young, 2017; Davison et al., 2018), attention needs to be directed toward offering HT in ways that acknowledge the diversity of immigrant fathers' experiences, cultural norms and preferences and their roles in family life. The development of health promotion programs for ethnically diverse fathers and children is in nascent stages (Perez et al., 2021; O'Connor et al., 2020; Griffin et al., 2019; Robertson et al., 2018) and remains an important focus for future research.

The findings of this study need to be considered in light of several limitations. Of particular importance is that data were not available regarding immigration status (immigrant or refugee) or length of time in Canada. In addition, dietary and physical activity patterns prior to immigration or current household food security were not assessed. The majority of caregiver respondents were female. Community organizations offered HT on weekdays during daytime hours and this would have been a barrier to attendance for fathers/male caregivers in full-time employment. The influence of these factors on views related to the acceptability of the program and program outcomes should be included in future evaluations. In addition, efforts should be made to include fathers/male caregivers from diverse immigrant groups in future research to determine how to support their inclusion in family health programs such as HT. Despite these limitations, the findings of this study provide directions for refining the HT program and for other family-focused interventions to support immigrant and refugee families.

\section{Conclusion}

The HT program model demonstrates strong potential to fill gaps in community programming promoting healthy lifestyles among immigrant and refugee families, as well as providing an avenue for building social connections and supporting family resettlement experiences. The findings contribute to the growing field of implementation studies that are focused on expanding the reach and impact of community health interventions in a realworld setting while reaching multiple target populations.

\section{References}

Amireault, S. and Godin, G. (2015), "The Godin-Shephard leisure-time physical activity questionnaire: validity evidence supporting its use for classifying healthy adults into active and insufficiently active categories", Perceptual and Motor Skills, Vol. 120 No. 2, pp. 604-622.

Bottorff, J.L., Huisken, A., Hopkins, M. and Friesen, L. (2021), "Scaling up a community-led health promotion initiative: lessons learned and promising practices from the healthy weights for children project", Evaluation and Program Planning, Vol. 87, p. 101943, doi: 10.1016/j.evalprogplan.2021.101943. 
Candib, L.M. (2007), "Obesity and diabetes in vulnerable populations: reflection on proximal and distal causes", The Annals of Family Medicine, Vol. 5 No. 6, pp. 547-556.

Davison, K.K., Kitos, N., Aftosmes-Tobio, A., Ash, T., Agaronov, A., Sepulveda, M. and Haines, J. (2018), "The forgotten parent: fathers' representation in family interventions to prevent childhood obesity", Preventive Medicine, Vol. 111, pp. 170-176.

Dawson-Hahn, E., Koceja, L., Stein, E., Farmer, B., Grow, H.M., Saelens, B.E., Mendoza, J. and PakGorstein, S. (2020), "Perspectives of caregivers on the effects of migration on the nutrition, health and physical activity of their young children: a qualitative study with immigrant and refugee families", Journal of Immigrant and Minority Health, Vol. 22 No. 2, pp. 274-281.

Forde, S.D., Lee, D.S., Mills, C. and Frisby, W. (2015), "Moving towards social inclusion: manager and staff perspectives on an award winning community sport and recreation program for immigrants", Sport Management Review, Vol. 18 No. 1, pp. 126-138.

Godin, G. and Shephard, R.J. (1985), "A simple method to assess exercise behavior in the community", Canadian Journal of Applied Sport Science, Vol. 10 No. 3, pp. 141-146.

Griffin, T., Sun, Y., Sidhu, M., Adab, P., Burgess, A., Collins, C., Daley, A., Entwistle, A., Frew, E., Hardy, P. and Hurley, K. (2019), "Healthy dads, healthy kids UK, a weight management programme for fathers: feasibility RCT”, BMJ Open, Vol. 9 No. 12, p. e033534.

Khan, M.M. and Kobayashi, K. (2017), "No one should be left behind: Identifying appropriate health promotion practices for immigrants", in Rootman, I., Peterson, A., Frohlich, K.L. and Dupere, S. (Eds), Health Promotion in Canada: New Perspectives on Theory, Practice, Policy, and Research, Canadian Scholars, Toronto, pp. 203-219.

Kipping, R.R., Jago, R. and Lawlor, D.A. (2008), "Obesity in children. Part 1: epidemiology, measurement, risk factors, and screening", BMJ, Vol. 337 No. oct153, p. a1824.

Lane, G., Farag, M., White, J., Nisbet, C. and Vatanparast, H. (2018), "Chronic health disparities among refugee and immigrant children in Canada", Applied Physiology, Nutrition, and Metabolism, Vol. 43 No. 10 , pp. 1043-1058

Lindsay, A.C., Sussner, K.M., Kim, J. and Gortmaker, S.L. (2006), "The role of parents in preventing childhood obesity", The Future of Children, Vol. 16 No. 1, pp. 169-186.

Morgan, P.J. and Young, M.D. (2017), "Investigating associations between positive fathering and children's health: it's time for interventions", Obesity, Vol. 25 No. 10, pp. 1650-1651.

O'Connor, T.M., Perez, O., Beltran, A., García, I.C., Arredondo, E., Cardona, R.P., Cabrera, N., Thompson, D., Baranowski, T. and Morgan, P.J. (2020), "Cultural adaptation of 'healthy dads, healthy kids' for hispanic families: applying the ecological validity model", International Journal of Behavioral Nutrition and Physical Activity, Vol. 17 No. 1, pp. 1-18.

Oliffe, J.L., Rossnagel, E., Bottorff, J.L., Chambers, S.K., Caperchione, C. and Rice, S.M. (2020), "Community-based men's health promotion programs: eight lessons learnt and their caveats", Health Promotion International, Vol. 35 No. 5, pp. 1230-1240.

Perez, O., Beltran, A., Isbell, T., Galdamez-Calderon, E., Baranowski, T., Morgan, P.J. and O'Connor, T. M. (2021), "Papás saludables, niños saludables: perspectives from hispanic parents and children in a culturally adapted father-focused obesity program", Journal of Nutrition Education and Behavior, Vol. 53 No. 3, pp. 246-253

Reilly, J.J. and Kelly, J. (2011), "Long-term impact of overweight and obesity in childhood and adolescence on morbidity and premature mortality in adulthood: systematic review", International Journal of Obesity, Vol. 35 No. 7, pp. 891-898.

Renzaho, A.M., Green, J., Smith, B.J. and Polonsky, M. (2018), "Exploring factors influencing childhood obesity prevention among migrant communities in Victoria, Australia: a qualitative study", Journal of Immigrant and Minority Health, Vol. 20 No. 4, pp. 865-883.

Robertson, S., Woodall, J., Henry, H., Hanna, E., Rowlands, S., Horrocks, J., Livesley, J. and Long, T. (2018), "Evaluating a community-led project for improving fathers' and children's wellbeing in England", Health Promotion International, Vol. 33 No. 3, pp. 410-421.

Robson, S.M., Stough, C.O. and Stark, L.J. (2016), "The impact of a pilot cooking intervention for parent-child dyads on the consumption of foods prepared away from home", Appetite, Vol. 99, pp. 177-184. 
Sahoo, K., Sahoo, B., Choudhury, A.K., Sofi, N.Y., Kumar, R. and Bhadoria, A.S. (2015), "Childhood obesity: causes and consequences", Journal of Family Medicine and Primary Care, Vol. 4 No. 2, pp. 187-192.

Sanou, D., O’Reilly, E., Ngnie-Teta, I., Batal, M., Mondain, N., Andrew, C., Newbold, B.K. and Bourgeault, I.L. (2014), "Acculturation and nutritional health of immigrants in Canada: a scoping review", Journal of Immigrant and Minority Health, Vol. 16 No. 1, pp. 24-34.

SiMPACT (2019), "Healthy Together SROI case study", Unpublished Report, SiMPACT Strategy Group, Toronto, Canada.

Statistics Canada (2017), "Census in brief children with an immigrant background: bridging cultures", available at: www12.statcan.gc.ca/census-recensement/2016/as-sa/98-200-x/2016015/98-200x2016015-eng.cfm (accessed August 19, 2019).

Thompson, P.D., Buchner, D., Piña, I.L., Balady, G.J., Williams, M.A., Marcus, B.H., Berra, K., Blair, S.N., Costa, F., Franklin, B. and Fletcher, G.F. (2003), "Exercise and physical activity in the prevention and treatment of atherosclerotic cardiovascular disease: a statement from the council on clinical cardiology (subcommittee on exercise, rehabilitation, and prevention) and the council on nutrition, physical activity, and metabolism (subcommittee on physical activity)", Circulation, Vol. 107 No. 24, pp. 3109-3116.

Tremblay, M.S., Bryan, S.N., Pérez, C.E., Ardern, C.I. and Katzmarzyk, P.T. (2006), "Physical activity and immigrant status", Canadian Journal of Public Health, Vol. 97 No. 4, pp. 277-282.

Tremblay, M.S., Pérez, C.E., Ardern, C.I., Bryan, S.N. and Katzmarzyk, P.T. (2005), "Obesity, overweight, and ethnicity", Health Reports, Vol. 16 No. 4, pp. 23-36.

Van Ryzin, M.J. and Nowicka, P. (2013), "Direct and indirect effects of a family-based intervention in early adolescence on parent- youth relationship quality, late adolescent health, and early adult obesity", Journal of Family Psychology, Vol. 27 No. 1, pp. 106-116.

Weiss, R., Dziura, J., Burgert, T.S., Tamborlane, W.V., Taksali, S.E., Yeckel, C.W., Allen, K., Lopes, M., Savoye, M., Morrison, J. and Sherwin, R.S. (2004), "Obesity and the metabolic syndrome in children and adolescents", New England Journal of Medicine, Vol. 350 No. 23, pp. 2362-2374.

Wieland, M.L., Tiedje, K., Meiers, S.J., Mohamed, A.A., Formea, C.M., Ridgeway, J.L., Asiedu, G.B., Boyum, G., Weis, J.A., Nigon, J.A. and Patten, C.A. (2015), "Perspectives on physical activity among immigrants and refugees to a small urban community in Minnesota", Journal of Immigrant and Minority Health, Vol. 17 No. 1, pp. 263-275

Zhang, Q., Liu, R., Diggs, L.A., Wang, Y. and Ling, L. (2019), "Does acculturation affect the dietary intakes and body weight status of children of immigrants in the US and other developed countries? A systematic review", Ethnicity and Health, Vol. 24 No. 1, pp. 73-93.

Zulfiqar, T., Strazdins, L., Banwell, C., Dinh, H. and D’Este, C. (2018), "Growing up in Australia: paradox of overweight/obesity in children of immigrants from low-and-middle-income countries", Obesity Science and Practice, Vol. 4 No. 2, pp. 178-187.

\section{Further reading}

Healthy Together (2019), "Healthy Together children's health program", available at: http://healthytogether.ca/ (accessed Sept 13, 2019).

\section{Corresponding author}

Joan L. Bottorff can be contacted at: joan.bottorff@ubc.ca

For instructions on how to order reprints of this article, please visit our website: www.emeraldgrouppublishing.com/licensing/reprints.htm

Or contact us for further details: permissions@emeraldinsight.com 